\title{
Behavioural reactivity of two lines of South African Merino sheep divergently selected for reproductive potential
}

\author{
Maud Bonato $^{\mathrm{a}, *}$, J.J.E. Cloete ${ }^{\mathrm{b}}$, A.C.M. Kruger ${ }^{\mathrm{c}}$, Schalk W.P. Cloete ${ }^{\mathrm{a}, \mathrm{c}}$

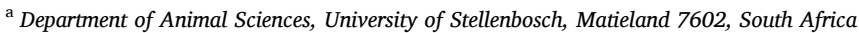 \\ ${ }^{\mathrm{b}}$ Western Cape Department of Agriculture, Elsenburg Agricultural Training Institute, Private Bag X1, Elsenburg 7607, South Africa \\ ${ }^{\mathrm{c}}$ Western Cape Department of Agriculture, Directorate Animal Sciences: Elsenburg, Private Bag X1, Elsenburg 7607, South Africa
}

\section{A R T I C L E I N F O}

\section{Keywords:}

Behavioural tests

Production performance

Temperament

Sheep

Stockman

\begin{abstract}
A B S T R A C T
The behavioural reactivity of two divergently selected lines of South African Merino sheep for an increased (HL: $\mathrm{N}=1187$ ) and reduced (LL: $\mathrm{N}=285$ ) number of lambs weaned per ewe mated was investigated using a docility test and a 'scale' test. The objective of this study was to determine whether these two lines, which differed significantly in terms of reproduction performance, would also react differently when exposed to novel and challenging situations. In the first test, an individual animal was moved to the test pen by an experienced handler then an unfamiliar or familiar human entered the test pen and tried to encourage the animal to move into a marked area for $3 \mathrm{~min}$. The test was terminated if the animal could not be moved within $3 \mathrm{~min}$, came out of the marked area or if the animal could be contained in the marked area for $30 \mathrm{~s}$ (successful test). The latency of the animal to enter and time contained in the square area was recorded as well as whether the animal was bleating or urinating/defecating during the test. No difference was found between production lines and handler in terms of the success of the test and latency to enter $(\mathrm{P}>0.05)$. LL sheep were however contained for longer and bleated more than HL sheep ( $\mathrm{P}<0.05)$. Sex differences were also observed, with ewes being more difficult to successfully contain and bleating more than rams, especially when exposed to an unfamiliar human $(\mathrm{P}<0.05)$. They also tended to urinate/defecate more than rams $(\mathrm{P}<0.05)$. In the second test, behaviour response of animals was recorded using a 5 -points score system $(1=$ calm; $5=$ wild) while spending $30 \mathrm{~s}$ on a scale. We also recorded whether animals were bleating during the test. While there was no difference in average scores between selection lines $(\mathrm{P}>0.05)$, inter-observer variability was observed $(\mathrm{P}<0.05)$. Ewes were also observed to bleat more than rams $(\mathrm{P}<0.05)$. Further research is needed to determine whether these and other behavioural tests are related to traits of economic importance in sheep.
\end{abstract}

\section{Introduction}

Farm animals have undergone the process of domestication, a continuing genetic process aiming at modifying the anatomy, physiology and the animal's behaviour so as to facilitate their adaption to man and the environment he provides (Siegel, 1993; Price, 2003). Having occurred over multiple generations, farm animals should be adapted to man and the captive environment, yet sudden changes in their social and physical environments and their exposure to people are the two commonest and potentially most stressful events encountered by animals (Suarez and Gallup, 1983; Jones, 1997; Zulfliki et al., 2013). As such, there is substantial evidence of a negative relationship between underlying fearfulness and productivity in farm animals (cattle: Voisinet et al., 1997; pigs: Hemsworth and Coleman, 1998; Hemsworth, 2003). For instance, Hemsworth and Coleman (1998) showed that pigs briefly but repeatedly exposed to a novel environment induced both behavioural and emotional reactions such as increased locomotive and escape attempts and vocalization, which also compromised growth and reproductive performance. In essence, this is because during time of stress, the animal redirects nutrients towards essential tissues (i.e. brain, heart, liver) leaving fewer nutrients available for growth, milk production, meat production and reproduction (Wynn, 1994).

To improve productivity and overall animal welfare, several authors have suggested the selection of temperament types that are well suited for specific production systems (Boissy et al., 2005; Ferguson and Warner, 2008). Temperament or emotional reactivity of animals can be

\footnotetext{
* Corresponding author at: Department of Animal Sciences, University of Stellenbosch, Private Bag X1, Matieland 7602, South Africa.

E-mail address: mbonato@sun.ac.za (M. Bonato).
} 
defined as the way an individual reacts to a novel and/or potentially stressful situation, both physiologically and behaviourally (Boissy and Bouissou, 1995; Reale et al., 2000). Poor temperament has been associated with reduced performance, impaired health, and compromised carcass quality in various livestock species (Gavojdian et al., 2015). Despite this, behavioural traits are rarely included in selection programs. However, as some temperament traits were found to have moderate to high heritability (Boissy et al., 2005; Hazard et al., 2020), a research shift towards the identification and selection of animals with temperaments that would improve welfare and productivity has now been advocated (Bikell et al., 2009; Dodd et al., 2012; Baciadonna et al., 2018).

Routine management procedures of sheep (i.e. shearing, castration, tail docking, horn trimming, vaccination, transportation etc.) all elicit physiological and behavioural stress responses which may also trigger a negative emotion such as fear (Boissy et al., 2005), adversely affecting productivity and welfare. Hence, behavioural reactivity of sheep to challenges has been the focus of many studies in an attempt to find predictive indicators of fear and emotionality. In general, all the tests involved placing animals under unfamiliar conditions and measuring their response in terms of behaviour (Murphy et al., 1994; Kilgour and Szantar-Coddington, 1995). Yet, when selecting animals on behavioural reactivity, it is also important to understand the impact on other aspects of productivity. In that sense, it was hypothesized that sheep of more quiet temperament grew faster and were better producers than animals that were restless, nervous or aggressive (Murphy et al., 1994; Cloete et al., 2005). Temperament was also related to the ability of ewes to rear their lambs whereby calmer ewes produced more lambs and weaned lambs earlier than agitated ewes (Murphy et al., 1994; Kilgour and Szantar-Coddington, 1995). All these results thus highlighted the potential benefits of selecting animals exhibiting lower levels of stress or fear for productivity and sheep welfare.

South Africa is home of more than 20 different sheep breeds. Sheep are often preferred by farmers as it allows sustainable production in extensive pastoral areas where no alternative farming ventures can be practiced (Cloete et al., 2014). The dominant wool breeds (Dohne Merino and Merino) account for more than half of the weaning weights registered at the National Small Stock Improvement Scheme, followed by the Dorper meat breed (Cloete and Olivier, 2010). Recent research has established behavioural reactivity differences between three widely divergent sheep breeds in South Africa (i.e. the Namaqua Afrikaner, Dorper and Mutton Merino: Cloete et al., 2013) which differs markedly in terms of production performance and resistance to parasites (Cloete et al., 2016). Yet, despite arena test studies undertaken by Cloete et al. (2005; 2013; 2017a; 2020), limited information is available on how and to what extent South African Merino (SAM) sheep experience and react to novel and challenging situations. However, these previous studies suggested that two lines of SAM divergently selected for more than 8 generations that differed substantially in their reproductive performance and product quality (number of lambs weaned: Cloete et al., 2004; lamb survival: Cloete et al., 2009; meat quality: Cloete et al., 2005) also differed in their behavioural response when confronted with a challenging situation during an arena test. Hence the aim of this study was to evaluate the behavioural reactivity and fear responses of these divergent selection lines by using two additional tests, namely a docility test and a scale-test. These tests studied different aspects of behaviour than the arena test, but some traits recorded, namely bleats and urination/defecation events were common across tests.

\section{Material and methods}

\subsection{Study population}

The experiment was conducted at the Elsenburg research farm of the Western Cape Department of Agriculture, South Africa, from 2014 to 2019 on nine-month-old SAM lambs $(\mathrm{N}=1472)$. The study animals originated from a resource flock that has been divergently selected for and against number of lambs weaned per ewe mated, resulting in a High Line (HL) and a Low Line (LL). Divergent selection as a scientific tool to assess genetic responses was described by Hill (1972). The selection lines were originally designed to provide timely information on the feasibility of changing a composite reproduction trait such as number of lambs weaned per ewe mated by genetic selection. Proof of the principle that number of lambs weaned per ewe mated responded to selection was provided by Cloete et al. (2004; 2017b). The importance of long-term selection lines, such as the resources used for this study, was recently reviewed by Hill (2011). While there seem to be a limited need for the establishment of new selection lines, the latter author argued for the maintenance of existing selection lines to further add to the present knowledge on the impact of quantitative trait selection in livestock. The present study is an example of using established genetic resources to gain new insights on the impact of selection on animal behaviour. The animals tested thus consisted of 1187 HL sheep and 285 LL sheep. Rams and ewes ( $N=719$ and 753 respectively) were assessed separately during the behavioural tests as they were maintained in flocks separated on sex. Ethical clearance was granted by the Western Cape Department of Agriculture (R12/57).

\subsection{Behavioural tests}

\subsubsection{Docility test}

The docility test was adapted from the work of Mazurek et al. (2011) to assess the ease of handling sheep. The test was conducted by two handlers (one familiar and one unfamiliar to the sheep) wearing similar clothing. Prior to the test, a group of animals (between 70 and 80) were drafted at random from the main flock and moved inside a barn. One animal at a time was caught by an experienced stockperson and moved gently to a $5 \mathrm{~m} \times 5 \mathrm{~m}$ test pen with a concrete floor in the surrounding sheep-yard to ensure that the tested individual did not have visual contact with its peers during the test. The animal was then identified through his/her ear tag, gently guided and released at the gate of the test pen, while the handler performing the test stood approximately $3 \mathrm{~m}$ away from the test pen gate. Each animal was given $30 \mathrm{~s}$ to familiarize his/herself with the test pen before the test started. Either the familiar or unfamiliar handler encouraged the animal to enter and remain in a square $(1.5 \mathrm{~m} \times 1.5 \mathrm{~m})$ marked out by spray paint on the concrete at a corner opposite of the gate of the testing pen for $30 \mathrm{~s}$, using slow arm movements and a calm voice. Each animal (ewes and rams) was tested once, either by the familiar or unfamiliar handler, while an observer, independent and unfamiliar to the animal, recorded the data from an elevated platform situated $20 \mathrm{~m}$ away from the testing pen. All participants were blind to the LL/HL designation of individual animals. The test was terminated if the animal was either contained in the square for $30 \mathrm{~s}$, could not be moved into the marked square within $3 \mathrm{~min}$ or if the animal escaped from the testing pen 3 times within the allocated time for testing. When an animal escaped the testing pen, the test was stopped and started over once the animal was brought back to the pen. The number of tries was also recorded. The latency to enter the marked square and duration of remaining there were recorded. Defecation, urination, all vocalizations (high- and low-pitched), number of jumps to escape from the testing pen were recorded as they may indicate stress during handling (Hemsworth et al., 2011; Dodd et al., 2012). After testing, the animal was moved to a different holding paddock, away and out of sight of the testing pen. Once all animals in the barn were tested, a different group was moved from the main flock to the barn to continue testing. All animals were tested once as the repeatability of similar measurements of temperament has been shown to be relatively high (Murphy et al., 1994).

\subsubsection{Scale-test}

Temperament of the lambs was assessed using the scale test method described by Pajor et al. (2010) and Dodd et al. (2012). This test consists 
of a subjective method used to evaluate behavioural reactivity and fear response to handling. For that purpose, the behaviour response of all animals was recorded using a 5-points score system while spending $30 \mathrm{~s}$ on a scale: 1 : calm with very little or no movements; 2 : low amplitude movements or less than 2 vigorous kicks or shakes; 3 : more than 2 vigorous kicks, shakes, jumps; 4: nearly continuous violent movements (with some brief pauses); and 5: continuous violent movements (no pause). The number of bleats produced by the sheep undergoing testing was also recorded. Three independent observers were trained to the scoring system prior to the start of the experiment. However, only one observer out of the two involved in scoring each year was consistent across all years. The other observer was one of two trained people as the same person was not always available owing to other commitments. However, all observers were blind to the designation of animals to either the LL or HL designation.

\subsection{Statistical analysis}

All statistical analyses were performed in $\mathrm{R}$ version 3.5.2 ( $\mathrm{R}$ Core Team, 2018). The docility test was analysed using General Linear Mixed Models (GLMM) with the latency of the sheep to enter the marked square and time contained within the marked square entered as dependent variables, while birth year (2013-2018), familiarity of handler (familiar or unfamiliar), sex (ram or ewe), selection line (high or low), age of the dam ( 2 to six years), birth type (i.e. single or multiple) and their interactions were entered as fixed factors, and the number of tries as a covariate. In addition, sire and dam identity (and their interactions) were entered as random factors. A similar model was used for the number of vocalization, urination/defecation events and jumps observed during the $3 \mathrm{~min}$ test. As the data to evaluate the success of containing the animals in the marked square area for $30 \mathrm{~s}$ were recorded in a binomial format (0: failure, 1: success), a logit link function of a similar GLMM was used to link the data to the normal distribution. The data were then reported as the logit link function back transformed predicted least-square means estimates.

The scale test was analysed by using a mixed effects ordinal regression of the lme4-package in $\mathrm{R}$, with the behavioural response of the sheep as the dependent variable, selection line, observer, age of the dam, birth type, birth year and their interactions were entered as fixed factors. In addition, identity of the sheep evaluated, sire and dam identity (and their interactions) were entered as random factors. A logit link function was used for this analysis. Finally, a GLMM was used with the number of vocalisation as the dependent variable, while birth year, observer, sex, line, age of the dam, birth type and their interactions were entered as fixed factors. In addition, sire and dam identity (and their interactions) and the identity of the sheep evaluated were entered as random effects.

\section{Results}

\subsection{Descriptive statistics of the docility and scale-test}

Overall, $62 \%$ of the sheep were successfully maintained in the marked square for $30 \mathrm{~s}$. It took (mean $\pm \mathrm{SE}$ ) $89.56 \pm 1.57 \mathrm{~s}$ for the sheep to enter the marked square and they were contained there for $22.46 \pm$ $0.30 \mathrm{~s}$ on average. The number of vocalizations produced during the test amounted to $2.77 \pm 0.13$ while the number of urinations/defecations amounted to $0.16 \pm 0.01$. Finally, the number of jumps observed during the test was $0.52 \pm 0.03$. During the scale test, a mean score of $1.97 \pm$ 0.02 was obtained, while the number of vocalizations amounted to 0.50 \pm 0.02 . No urination or defecation was observed during this test.

\subsection{Effect of fixed factors on success of the test, time to enter and time maintained in the marked square during the docility test}

No difference between selection line, handler, age of the dam or birth type was observed with regards to the success of the test $(P>0.05)$.
However, differences were recorded between sexes whereby a higher success rate was observed for males as compared to females $(69 \pm 5 \%$ vs. $63 \pm 5 \%$, respectively; $\mathrm{Z}$ value $=3.416, \mathrm{P}<0.05$ ). Furthermore, birth year also had an effect on success rate achieved $(Z$ value $=-3.006$, $\mathrm{P}<0.05$ ). Concerning the latency to enter the marked area, only birth year of the sheep had a significant effect $\left(\mathrm{F}_{5,175}=3.91, \mathrm{P}=0.002\right)$.

Finally, a difference between selection lines was observed for the latency to be contained in the marked area $(\mathrm{P}<0.05)$. Sheep from the LL line were contained for longer than sheep from the HL line (LL: $24.6 \pm$ 1.14 s; HL: $\left.22.3 \pm 0.85 ; \mathrm{F}_{1,80}=4.11, \mathrm{P}=0.04\right)$. Birth year also affected this variable $\left(\mathrm{F}_{5,196}=4.03, \mathrm{P}=0.002\right)$.

\subsection{Effect of fixed factors on the number of vocalizations, urinations/ defecations and jumps during the docility test}

The number of vocalizations recorded during the test was significantly affected by selection line, sex, birth year and the interaction between sex and familiarity of the handler $(\mathrm{P}<0.05)$. Sheep from the LL line bleated more often than sheep from the HL line $(3.20 \pm 0.44$ and $2.17 \pm 0.33$, respectively; $\mathrm{F}_{1,102}=5.55, \mathrm{P}=0.02$ ), and females (irrespective of selection line) also bleated more than males ( $3.47 \pm 0.35$ and $1.90 \pm 0.36$, respectively; $F_{1,1439}=25.08, P<0.001$ ). Furthermore, while no differences in the number of vocalizations was observed between sexes when exposed to the familiar handler during the test, females bleated more than males when exposed to the unfamiliar handler $\left(\mathrm{F}_{1,1451}=4.19, \mathrm{P}=0.04\right.$; Fig. 1$)$.

The number of urinations/defecations only differed between sexes, with females urinating/defecating more often than males $(0.32 \pm 0.03$ and $0.02 \pm 0.03$ respectively; $F_{1,1449}=111.74, P<0.0001$ ). Finally, the number of jumps observed during the test was affected by selection line and birth year $(\mathrm{P}<0.05)$. HL sheep jumped more often than LL sheep $\left(0.57 \pm 0.09\right.$ and $0.25 \pm 0.13$ respectively; $\left.F_{1,56}=5.79, \mathrm{P}=0.02\right)$.

\subsection{Effect of fixed factors on score and number of vocalizations during the scale-test}

While no difference was observed between selection lines in terms of scores allocated $(\mathrm{P}>0.05)$, scores differed significantly between observers $\left(\mathrm{F}_{2,1514}=16.54, \mathrm{P}<0.001\right)$ and birth year $\left(\mathrm{F}_{5,202}=24.55, \mathrm{P}<\right.$ $0.001)$. Furthermore, in contrast to the docility test, there was no difference between selection lines for the number of vocalizations $(\mathrm{P}>$

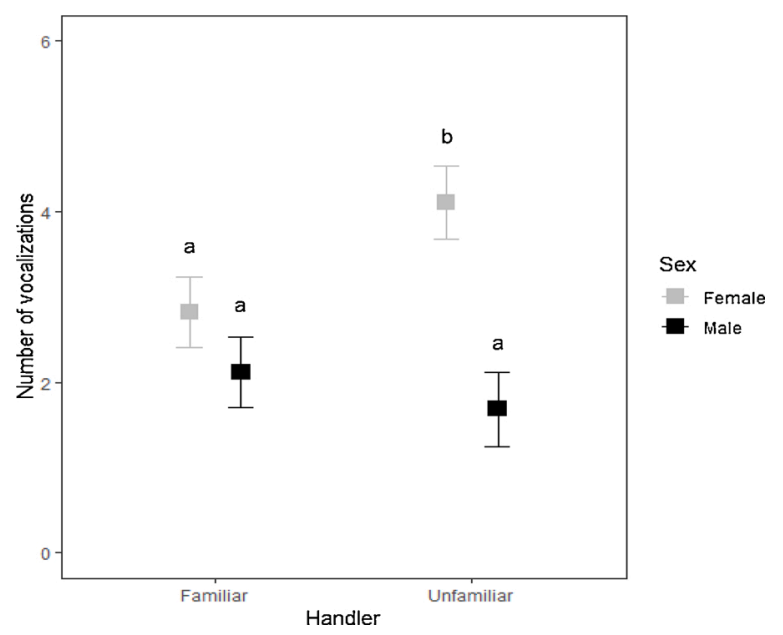

Fig. 1. Least-square means depicting the effect of familiarity of handler on the number of vocalizations of male $(\mathrm{N}=719)$ and female $(\mathrm{N}=753)$ nine months old South African Merino lambs during the docility test. Boxes indicate the LS mean. Error bars indicate the $95 \%$ confidence interval around the LS mean. Means sharing a common superscript are not significantly different (Tukey-adjusted comparisons). 
0.05). However, females bleated more often than males ( $0.52 \pm 0.10$ and $0.35 \pm 0.10$ respectively; $\left.\mathrm{F}_{1,1642}=24.55, \mathrm{P}<0.0001\right)$ and differences were also observed between birth years $\left(\mathrm{F}_{5,202}=24.55, \mathrm{P}<0.001\right)$.

\section{Discussion}

\subsection{The effects of selection line}

Previous research on the same resource flock highlighted that sheep selected for reproduction displayed behavioural repertoires indicating lower levels of stress associated with their exposure to humans. For instance, HL sheep were more willing to approach a stationary human observer (Cloete et al., 2005, 2017a), travelled longer distances, urinated or defecated less (Cloete et al., 2017a, 2020) and bleated less (Cloete et al., 2020) when challenged during an arena test than LL sheep. The findings of the present study are thus consistent with this as LL sheep experienced unfamiliar situations as more stressful than HL sheep, more specifically when they were isolated from the flock. For instance, LL sheep were contained for longer and bleated more than HL sheep during the docility test, thereby confirming their unease with the contrived situation.

Being social animals, sheep perceive the isolation from conspecifics even for short period as one of the most stressful and fear eliciting situations, prompting significant behavioural and physiological perturbations (Boissy et al., 2005; Barnard et al., 2015). Shy and/or stressed animals not only tend to keep their distance from any potential elements they consider as a threat or as an alteration to their environment but they also tend to express their distress by vocalizing more. Standing in the same position and at the same place can thus be an indicator of behavioural inhibition, signifying a more passive, rather than active, reaction to a stressful situation (Romeyer and Bouissou, 1992; Vandenheede et al., 1998). On the contrary, calm/bold animals will explore their new environment, whilst also trying to find ways of getting to a more desirable place. This is also in accordance with our observation as HL sheep tended to be more active (i.e. they jumped more often) than the LL sheep, in an attempt to either re-join their flock mates or access / reach a more comfortable situation. Cloete et al. (2017a; 2020) accordingly reported that animals from the high line travelled longer distances during the arena test, a behavioural response to an urge to explore and access a more desirable situation. Being unwilling to be contained by a mobile human for an extended period also corresponds to this line of reasoning.

The link between temperament of livestock and productive losses is well-documented in several livestock species (cattle: Sutherland et al., 2012; Friedrich et al., 2015; pigs: Hansson et al., 2005; D'Eath et al., 2010). In sheep specifically, temperament has been demonstrated to affect lamb survival and growth rate (Pajor et al., 2008; Gavojdian et al., 2015), meat quantity and quality (Ferguson and Warner, 2008), as well as productive and reproductive performance (Murray et al., 2009; Blache and Bickell, 2011; Dodd et al., 2012; Gavojdian et al., 2015). Within the context of the present study, Cloete et al. (2004) demonstrated that ewes from the LL not only typically weaned fewer lambs, but they also lambed later in the lambing season compared to HL sheep. In a later paper, they further demonstrated that LL sheep had a significantly lower physical meat production and quality as shown by their lower slaughter weight, dressing percentage, carcass weight and post-mortem pH-decline (Cloete et al., 2005). Hence we would like to propose a working hypothesis that the difference in behavioural reactivity observed between these two lines in the arena test (Cloete et al., 2020) and in the docility test of the present study follows as a correlated response on the divergent selection practiced in the resource flock. From this it follows that the poorer performance in LL sheep also stems from this correlated response. These arguments are supported by studies conducted on other flocks of Merino rams and ewes. For instance, Kilgour and Szantar-Coddington (1995); Kilgour (1998) and Kilgour et al. (2006) observed that a flock of sheep selected for improved fertility was less agitated and bleated less than sheep from an unselected flock. In parallel to that, successful selection for temperament resulting in lines differing in their reactivity during behavioural tests was also achieved on several occasions in Merino sheep (Amdi et al., 2010; Beausoleil et al., 2008; Blache and Ferguson, 2005). As Cloete et al. (2017a; 2020) demonstrated that the behaviour displayed by SAM sheep of the same flock in an arena test was heritable it is evident that modification of temperament through selection based on behavioural reactivity scores is achievable. This line of reasoning could be developed to assist in achieving better production performance while also improving the welfare of sheep in particular and farm animals in general in tandem with advantages in productivity.

\subsection{The effect of the sex of the animal}

Sheep temperament has been demonstrated to differ between sexes across a variety of behavioural tests (arena test: Boissy et al., 2005; surprise test: Vandenheede and Bouisson, 1993; isolation test: Hernandez et al., 2010). In all instances, ewes were more active than rams: they moved, tried to escape and bleated more often than rams, indicating that they were more sensitive and subsequently more stressed when exposed to novel situations. Our results are consistent with this pattern. Ewes had an overall lower success rate during the docility test as compared to rams (i.e. they were harder to contain within the designated area for the pre-defined amount of time). They also consistently bleated more during both tests as was previously also reported by Cloete et al. (2017a; 2020), and urinated/defecated more often than rams during the docility test. Furthermore, ewes appeared to be able to differentiate between a familiar and an unfamiliar handler, as revealed by the higher frequency of bleats when exposed to the unfamiliar handler. This ability to distinguish between familiar and unfamiliar humans has been reported at several occasions in different livestock species (pigs: Tanida and Nagano, 1998; cattle: Munksgaard et al., 1999; ostriches: Muvhali et al., 2018; sheep: Boivin et al., 1998; Cannas et al., 2018) and is thus likely to have welfare and production implications. Within the context of ewe temperament, several studies have highlighted how the ability to cope with potentially stressful situations can influence maternal behaviourial repertoires at lambing (Kilgour and Szantar-Coddington, 1995; Pajor et al., 2010; Hough et al., 2013), and thus determine offspring behaviour, health and productivity (Dodd et al., 2012; Dwyer, 2014; Rooke et al., 2017). Considering that the bulk of animals on a productive farm consists of reproducing ewes, management practices that accommodate the biology and preference of the ewe should be implemented to ensure optimal maternal care and hence promote the welfare of the ewe, lamb, as well as the profitability of the farm.

When animals are subjected regularly to handling during, for instance, routine husbandry practices, it is not uncommon to observe a reduction in fearful responses towards humans in farm livestock (Boissy et al., 2002; Zulkifli, 2013). The resource flock used for the present study is commonly used for research purposes which involve different degrees of interactions with humans (i.e. behavioural tests; assisted reproductive technology projects; genetics and selection etc.; see Cloete et al., 2005, 2017a; Boshoff, 2014). Although the pattern of variation observed between birth years is relatively unclear, variation in human exposure over the years and generations of sheep might at least partially explain some differences observed for several variables, making the animals occasionally more sensitive to specific aspects of the behavioural tests conducted (i.e. isolation from the flock: docility test; restraint: scale-test).

Values attributed to the reactivity score during the scale-test varied significantly between observers. A variety of studies have reported the inter-observer variability of a range of behavioural assessments (Caro et al., 1979; Waiblinger et al., 2007; Tuyttens et al., 2014). Such phenomena are particularly prevalent in experiments requiring some degree of interpretation and subjective judgement when recording or scoring behavioural observations. The scale-test is a relatively quick and easy on-farm method to assess behavioural reactivity of animals during 
weighing as a routine operation (and assess their welfare at the same time). However, it is primordial to properly train assessors in recognizing "normal" behaviour of the animal under investigation (Knierim and Winckler, 2009; Plythian et al., 2013), but also to test inter- and intra-observer reliability so as to minimize any potential observer bias (Martin and Bateson, 1993; Dawkins, 2007).

\section{Conclusion}

This study showed that HL animals, when confronted to a change in their environment and to humans in particular, were better able to cope with such potentially stressful situations than LL animals. In addition, females appeared to be more agitated than males during both tests, and more sensitive to the presence of an unfamiliar handler. Further studies are required to determine whether these differences in behavioural reactivity and fear response between lines and sexes are genetically related to other traits such as growth, wool output and quality, or product quality. The suggestion of a realized genetic correlation in behaviour following divergent selection in the flock studies should also be followed up with formally deriving the genetic correlation between number of lambs weaned per ewe and offspring behaviour. Furthermore, the inter-observer variability recorded during the scale-test stresses the need to pin-point and to evaluate factors that could contribute to this variation, as well as to provide adequate training to observers especially within the growing prominence of welfare assessments of livestock and captive species.

\section{Declaration of Competing Interest}

The authors reported no declarations of interest.

\section{Acknowledgements}

We express our sincere gratitude to the Western Cape Department of Agriculture and the Elsenburg Research Farm for the usage of the resource flock and facility. We are also grateful to all members of the staff of the research farm, and especially Davey Marang for assistance in data recording and taking care of the animals. Funding was provided by the Western Cape Agricultural Research Trust and the National Research Foundation (NRF) of South Africa through their THRIP program.

\section{References}

Amdi, C., Williams, A.R., Maloney, S.K., Tauson, A.H., Knott, S.A., Blache, D., 2010. Relationship between behavioural reactivity and feed efficiency in housed sheep. Anim. Prod. Sci. 50, 683-687.

Baciadonna, L., Dueplan, S., Briefer, E.F., Pacilla de la Torre, M., Nawroth, C., 2018. Looking on the bright side of livestock emotions - the potential of their transmission to promote positive welfare. Front. Vet. Sci. 5, 1-6.

Barnard, S., Matthews, L.R., Messori, S., Podaliri, Vulpiani, M., Ferri, N., 2015. Behavioural reactivity of ewes and lambs during partial and total social isolation. Appl. Anim. Behav. Sci. 163, 89-97.

Beausoleil, N.J., Blache, D., Stafford, K.J., Mellor, D.J., Noble, A.D.L., 2008. Exploring the basis of divergent selection for 'temperament' in domestic sheep. Appl. Anim. Behav. Sci. 109, 261-274.

Blache, D., Bickell, S., 2011. External and internal modulators of sheep reproduction. Reprod. Biol. 11, 61-77.

Blache, D., Ferguson, D., 2005. Boost Lamb Survival-select for Calm Ewes. Department of Agriculture, Western Australia. Available at: http://archive.agric.wa.gov.au. Accessed April 3, 2020.

Boissy, A., Bouissou, M.F., 1995. Assessment of individual differences in behavioural reactions of heifers exposed to various fear-eliciting situations. Appl. Anim. Behav. Sci. 46, 17-31.

Boissy, A., Fisher, A., Bouix, J., Boivin, X., Le Niendre, P., 2002. Genetics of fear and fearfulness in domestic herbivores. Proceedings of the Seventh World Congress General Application Livestock Production 32, 3-10 August 2002, Montpellier, France.

Boissy, A., Bouix, J., Orgeur, P., Poindron, P., Bibe, B., Le Neindre, P., 2005. Genetic analysis of emotional reactivity in sheep : effects of the genotypes of the lambs and of their dams. Genet. Sel. Evol. 37, 381-401.

Boivin, X., Garel, J.P., Mante, A., Le Neindre, P., 1998. Beef calves react differently to different handlers according to the test situation and their previous interactions with their caretaker. Appl. Anim. Behav. Sci. 55, 245-257.
Boshoff, N.H., 2014. The Influence of Genotype on Sperm Motility and Sperm Head Morphometry of Merino (Ovis Aries) Sheep. MSc thesis. University of Stellenbosch, Stellenbosch, South Africa.

Cannas, S., Palestrini, C., Canali, E., Cozzi, B., Ferri, N., Heinzl, E., Minero, M., Chincarini, M., Vignola, G., Dalla Costa, E., 2018. Thermography as a non-invasive measure of stress and fear of humans in sheep. Animals 8, 1-7.

Caro, T.M., Roper, R., Young, M., Dank, G.R., 1979. Inter-observer reliability. Behaviour 69, 303-315.

Cloete, S.W.P., Olivier, J.J., 2010. South African sheep and wool industry. In: Cottle, D.J. (Ed.), International Sheep and Wool Handbook. Nottingham University Press, pp. 95-112.

Cloete, S.W.P., Gilmour, A.R., Olivier, J.J., van Wyk, J.B., 2004. Genetic and phenotypic trends and parameters in reproduction, greasy fleece weight and live weight in Merino lines divergently selected for multiple rearing ability. Aust. J. Exp. Agric. 44, 745-754.

Cloete, J.J.E., Cloete, S.W.P., Hoffman, L.C., 2005. Behaviour of Merinos divergently selected for multiple rearing ability in response to external stimuli. Small Rumin. Res. 60, 227-236.

Cloete, S.W.P., Misztal, I., Olivier, J.J., 2009. Genetic parameters and trends for lamb survival and birth weight in a Merino flock divergently selected for multiple rearing ability. J. Anim. Sci. 87, 2196-2208.

Cloete, J.J.E., Cloete, S.W.P., Scholtz, A.J., Hoffman, L.C., 2013. Behaviour response of Namaqua Afrikaner, Dorper and South African mutton merino lambs towards humans. S. Afr. J. Anim. Sci. 43, S116-S120.

Cloete, S.W.P., Olivier, J.J., Sandenbergh, L., Snyman, M.A., 2014. The adaption of the South Africa sheep industry to new trends in animal breedingand genetics : a review. S. Afr. J. Anim. Sci. 44, 307-321.

Cloete, S.W.P., Cloete, J.J.E., Scholtz, A.J., 2016. Genetic parameters for tick count and udder health in commercial and indigenous ewes in South Africa. Vet. Parasitol. 230, $33-42$.

Cloete, J.J.E., Scholtz, A.J., Cloete, S.W.P., 2017a. Genetic parameters for arena behaviour of lambs from Merinos divergently selected for lambs weaned per ewe mated. Proc. Assoc. Advmt. Anim. Breed. Genet. 22, 577-580.

Cloete, S.W.P., Van Wyk, J.B., Olivier, J.J., 2017b. Genetic responses in component and composite reproduction traits in Merino ewes divergently selected for number of lambs weaned. Proc. Assoc. Advmt. Anim. Breed. Genet. 22, 569-572.

Cloete, S.W.P., Burger, M., Scholtz, A.J., Cloete, J.J.E., Kruger, A.C.M., Dzama, K., 2020. Arema behaviour of Merino weaners is heritable and affected by divergent selection of number of lambs weaned by ewe mated. Appl. Anim. Behav. Sci. 233, 1-11.

D'Eath, R., Turner, S., Kurt, E., Evans, G., Thölking, L., Looft, H., Wimmers, K., Murani, E., Klont, R., Foury, A., Ison, S.H., Laurence, A.B., Mormède, P., 2010. Pigs' aggressive temperament affects pre-slaughter mixing aggression, stress and meat quality. Animal 4, 604-616.

Dawkins, M.S., 2007. Observing Animal Behaviour: Design and Analysis of Quantitative Data. Oxford University Press, Oxford, UK.

Dodd, C.L., Pitchford, W.S., Hocking Edward, J.E., Hazel, S.J., 2012. Measures of behavioural reactivity and their relationships with production traits: a review. Appl. Anim. Behav. Sci. 140, 1-15.

Dwyer, C.M., 2014. Maternal behaviour and lamb survival: from neuroendocrinology to practical application. Animal. 8, 102-112.

Ferguson, D.M., Warner, R.D., 2008. Have we underestimated the impact of preslaughter stress on meat quality in ruminants? Meat Sci. 80, 12-19.

Friedrich, J., Brand, B., Schwerin, M., 2015. Genetics of cattle temperament and its impact on livestock production and breeding - a review. Arch. Anim. Breed. 58, $13-21$.

Gavojdian, D., Cziszter, L.T., Budai, C., Kusza, S., 2015. Effects of behavioral reactivity on production and reproduction traits in Dorper sheep breed. J. Vet. Behav. 10, 365-368.

Hansson, A.C., Crump, R.E., Graser, H.U., Sokolinski, R., 2005. Relationships among temperament and production traits of pigs. Proc. Assoc. Advmt. Anim. Breed. Genet. $16,141-144$.

Hazard, D., Macé, T., Kempeneers, A., Delval, E., Foulquié, D., Bouix, J., Boissy, A., 2020. Genetic parameters estimates for ewes' behavioural reactivity towards their litter after lambing. J. Anim. Breed. Genet. 137, 374-383. https://doi.org/10.1111/ jbg.12474.

Hemsworth, P.H., 2003. Human-animal interactions in livestock production. Appl. Anim. Behav. Sci. 85, 185-198.

Hemsworth, P.H., Coleman, G.J., 1998. Human-Livestock Interactions: The Stockperson and the Productivity and Welfare of Intensively Farmed Animals. CAB International, Wallingford.

Hemsworth, P.H., Rice, M., Karlen, M.G., Calleja, L., Barnett, J.L., Nash, J., Coleman, G. J., 2011. Human-animal interactions at abattoirs: relationships between handling and animal stress in sheep and cattle. Appl. Anim. Behav. Sci. 135, 24-33.

Hernandez, C.E., Matthews, L.R., Oliver, M.H., Bloomfield, F.H., Harding, J.E., 2010. Effects of sex, litter size and periconceptional ewe nutrition on offspring behavioural and physiological response to isolation. Physiol. Behav. 101, 588-594.

Hill, W.G., 1972. Estimation of realised heritabilities from selection experiments I. Divergent selection. Biometrics 28, 747-765.

Hill, W.G., 2011. Can more be learned from selection experiments of value in animal breeding programmes? Or is it time for an obituary? J. Anim. Breed. Genet. 128, 1-8.

Hough, D., Swart, P., Cloete, S.W.P.S., 2013. Exploration of the hypothalamicpituitaryadrenal axis to improve animal welfare by means of genetic selection: lessons from the South African Merino. Animals 3, 442-474.

Jones, R.B., 1997. Fear and distress. In: Appleby, M.C., Hughes, B.O. (Eds.), Animal Welfare, 1997. CAB International, Wallingford, pp. 75-88. 
Kilgour, R.J., 1998. Arena behaviour is a possible selection criterion for lamb-rearing ability: it can be measured in young rams and ewes. Appl. Anim. Behav. Sci. 57, 81-89.

Kilgour, R.J., Szantar-Coddington, M.R., 1995. Arena behaviour of ewes selected for superior mothering ability differs from that of unselected ewes. Anim. Reprod. Sci. 37, 133-141.

Kilgour, R.J., Melville, G.J., Greenwood, P.L., 2006. Individual differences in the reaction of beef cattle to situations involving social isolation, close proximity of humans, restraint and novelty. Appl. Anim. Behav. Sci. 99, 21-40.

Knierim, U., Winckler, C., 2009. On-farm assessment in cattle: validity, reliability, and feasibility issues and future perspectives with special regard to the Welfare Quality approach. Anim. Welfare. 18, 451-458.

Martin, P., Bateson, P., 1993. Measuring Behaviour: an Introductory Guide, 2nd ed. Cambridge University Press, Cambridge, UK.

Mazurek, M., McGee, M., Crowe, M.A., Prendiville, D.J., Boivin, X., Earley, B., 2011. Consistency and stability of behavioural fear responses of heifers to different feareliciting situations involving animals. Appl. Anim. Behav. Sci. 131, 21-28.

Munksgaard, L., de Passille, A.M., Rushen, J., Ladewig, J., 1999. Dairy cows' use of colour cues to discriminate between people. Appl. Anim. Behav. Sci. 65, 1-11.

Murphy, P.M., Purvis, I.W., Lindsay, D.R., Le Neindre, P., Orgeur, P., Poindron, P., 1994. Measures of temperament are highly repeatable in Merino sheep and some are related to maternal behaviour. Proc. Aust. Soc. Anim. Prod. 20, 247-250.

Murray, T.L., Blache, D.B., Bencini, R., 2009. The selection of dairy sheep on calm temperament before milking and its effect on management and milk production. Small Rumin. Res. 87, 45-49.

Muvhali, P.T., Bonato, M., Engelbrecht, A., Malecki, I.A., Hough, D., Robinson, J.E., Evans, N.P., Cloete, S.W.P., 2018. The effect of extensive human presence at an early age on stress responses and reactivity of juvenile ostriches towards humans. Animals 8, 175. https://doi.org/10.3390/ani8100175.

Pajor, F., Szentleleki, A., Laczo, E., Tőzser, J., Poti, P., 2008. The effect of temperament on weight gain of Hungarian Merino, German Merino and German Blackhead lambs. Arch. Tierz. 51, 247-254.

Pajor, F., Muranyi, A., Szentleleki, A., Tozser, J., Poti, P., 2010. Effect of temperament of ewes on their maternal ability and their lambs' postweaning traits in Tsigaei breed. Arch Tierzucht 4, 465-474.

Plythian, C., Michalopoulou, E., Duncan, J., Wemeldfelder, F., 2013. Inter-observer reliability of qualitative behavioural assessments of sheep. Appl. Anim. Behav. Sci. 144, 73-79.
Price, E.O., 2003. Animal Domestication and Behavior. CABI Publ., New York.

R Core Team, 2018. R: a Language and Environment for Statistical Computing. R Foundation for Statistical Computing, Vienna, Austria. https://www.R-project.org/.

Reale, D., Gallant, B.Y., Leblanc, M., Festa-Bianchet, M., 2000. Consistency of temperament in bighorn ewes and correlates with behavior and life history. Anim. Behav. 60, 589-597.

Romeyer, A., Bouissou, M.F., 1992. Assessment of fear reactions in domestic sheep, and influence of breed and rearing conditions. Appl. Anim. Behav. Sci. 34, 93-119.

Rooke, J.A., Arnott, G., Dwyer, D.M., Rutherford, K.M.D., 2017. Impact of maternal stress and nutrition on behavioural and physiological outcomes in young lambs. Anim. Welfare. 26, 403-415.

Siegel, P.B., 1993. Behavior-genetic analyses and poultry husbandry. Poult. Sci. 72, 1-6.

Suarez, S.D., Gallup, G.G., 1983. Open-field behaviour in chickens: the experimenter is a predator. J. Comp. Physiol. Psycho. 96, 432-439.

Sutherland, M.A., Rogers, A.R., Verkerk, G.A., 2012. The effect of temperament and responsiveness towards humans on the behavior, physiology and milk production of multi-parous dairy cows in a familiar and novel milking environment. Physiol. Behav. 107, 329-337.

Tanida, H., Nagano, Y., 1998. The ability of miniature pigs to discriminate between a stranger and their familiar handler. Appl. Anim. Behav. Sci. 56, 149-159.

Tuyttens, F.A.M., de Graaf, S., Heerkens, J.L.T., Jacobs, L., Nalon, E., Ott, S., Stadig, L., Van Laer, E., Ampe, B., 2014. Observer bias in animal behaviour research: can we believe what we score, if we score what we believe? Anim. Behav. 90, 273-280.

Vandenheede, M., Bouisson, M.F., 1993. Sex differences in fear reactions in sheep. Appl. Anim. Behav. Sci. 37, 39-55.

Vandenheede, M., Bouissou, M.F., Picard, M., 1998. Interpretation of behavioural reactions of sheep towards fear-eliciting situations. Appl. Anim. Behav. Sci. 58, 293-310.

Voisinet, B.D., Grandin, T., Tatum, J.D., O' Connor, S.F., Struthers, J.J., 1997. Feedlot cattle with calm temperaments have higher average daily gains than cattle with excitable temperaments. J. Anim. Sci. 75, 892-896.

Waiblinger, S., Mulleder, C., Schmied, C., Dembele, I., 2007. Assessing the animals'relationship to humans in tied dairy cows: between-experimenter repeatability of measuring avoidance reactions. Anim. Welfare. 16, 143-146.

Wynn, P.C., 1994. The influence of stress on animal productivity. Proc. Aust. Sot. Anim. 20, 65-66.

Zulkifli, I., 2013. Review of human-animal interactions and their impact on animal productivity and welfare. J. Anim. Sci. Biotechno. 4, 1-7. 